\title{
EngCon: A Pre-CAPSTONe EngineERING Design CONVENTION
}

\author{
Chris Rennick and Eugene Li \\ University of Waterloo \\ chris.rennick@uwaterloo.ca, eugene.1i@uwaterloo.ca
}

\begin{abstract}
The capstone design project is ubiquitous in engineering programs worldwide, and is seen by students as the single most important activity in their undergraduate careers. Staff and faculty at the University of Waterloo identified three issues with the current capstone process: students are unaware of industrial suppliers, they lack multi-disciplinary exposure, and they often struggle to identify "good" needs for their projects.

The Engineering IDEAs Clinic, with support from instructors and staff from across Engineering, developed a conference for students to address these issues. EngConaimed at students in third/fourth year - brought students together with their peers from other programs, instructors from across the Faculty, and representatives from suppliers (both external industry, and internal support units) with the goal of improving their capstone projects.

This paper presents the design and implementation of EngCon in both 2017 and 2018 with lessons learned from offering a large coordinated set of workshops aimed at students as they enter their capstone design projects.
\end{abstract}

Keywords: Needs analysis, Design practice, Design process, Extracurricular

\section{INTRODUCTION}

The senior capstone design project - 8-12 months long and designed to resemble real engineering practice - is the single most significant design experience in which engineering students participate at Waterloo. Good capstone projects can lead to desirable employment and even commercialization into entrepreneurial start-ups (see [1] as one example). Students are typically highly motivated to succeed in their capstone experience, and while they have obtained the requisite factual knowledgebase through their prior academic work, they are often lacking the experiential knowledge-base (or "know-how") described by Frise et al [2]. This know-how can be obtained through many means, though too often is left to extra-curriculars: work placements, co-operative employment, work on student teams, or through projects conducted in/outside of class.
In early 2017, staff and faculty at the University of Waterloo identified three shortcomings in the current capstone process:

1. Students are unaware of the companies that supply components to industry, and so often reinvent the wheel which hurts their overall project quality, and costs them valuable time

2. Students lack multi-disciplinary exposure, and due to the highly siloed nature of engineering programs, rarely interact with their peers or instructors from other programs

3. Students struggle to identify "good" needs or problems that need to be solved

Traditional design theories [3], including the very popular design thinking approach [4] describe the following stages of the design process: need assessment (or empathizing), problem definition, concept generation (or ideation), implementation (or prototyping), and verification/evaluation (or testing). If the goal of capstone is to provide students with one more structured opportunity to experience the full design process, part of that must be a focus on the need identification/assessment stage. Unfortunately, the capstone project is often the first time students are tasked with identifying a need on their own in the context of a design problem, and many struggle with needs identification. This results in lower quality projects, as the quality of the capstone project largely depends on identifying a suitable real need or problem to address in the design. Often, students take a solution-first approach, and then "reverse engineer" a need to justify capstone course requirements. This results in weak solutions and incomplete exposure to the full design process.

\subsection{Existing Approaches}

Being able to identify the needs of society and addressing them are one of the basic tenants of engineering. This is a critical skill to ensure that the profession of engineering remains relevant to the public good. With this in mind, nearly all engineering programs across Canada make it a priority and teach needs analysis in first year introductory engineering courses. Texts such as 
"Introduction to Professional Engineering in Canada" [5] remain a staple in many engineering programs and act as a first introduction for many students.

Although the relevance and importance of identifying needs is stressed to budding engineers, many programs quickly shift the focus from defining the needs statement to turning the needs statement into engineering specifications and criteria and constraints. With clearly defined criteria and constraints, traditional engineering design methodology can be applied.

This method of teaching and focus does well to train capable and technically sound engineers. The critical points of the engineering design cycle are well maintained and re-enforced throughout labs, assignments and exams. Engineering students are very capable of taking a problem and identifying the crucial aspects of it, and then designing a solution. However, when faced with defining their own meaningful problems, they too often flounder.

When challenged to find a problem of their own choosing, engineering students have limited experience in identifying relevant problems, and often end up choosing trivial problems or ones that are near impossible to solve. Likewise, students have not practiced using the research skills that are required to fully describe the state of the art in a particular industry, often leading them to solve problems that have already been solved by others. As with many "soft" skills, engineering programs assume that these skills will be taught in the workplace and come with experience. While this may be true, it does not need to be the case.

In other fields of study, such as business administration, students are often taught a systematic way to identify relevant problems that are open to varied solutions. Following the models set forth by Kaufman [6], needs can be defined as the "gaps" between current conditions and desired conditions. These systematic approaches have been applied in education [6] and medicine [7] and have shown a definite impact on the quality of their graduates.

\section{PILOT IMPLEMENTATION}

In an effort to address concerns with the capstone design projects at the University of Waterloo, the Engineering IDEAs Clinic developed a one-day conference called "EngCon" for undergraduates that addressed many of the common problems across engineering disciplines. These problems focused on technical and non-technical aspects associated with engineering development and capstone design. The conference in 2017 was aimed primarily at the approximately 350 students from the departments of Mechanical and Mechatronics Engineering (MME), and Electrical and Computer Engineering (ECE) in their second semester of third year (3B), or their first semester of fourth year (4A). Due to the mandatory co-op in Engineering at the University of Waterloo (with different timing program to program), not all students are on campus in a given term. It was felt that early in the fall semester would catch the most students either just before they enter their capstone project (3B), or as they are just getting started on their projects (4A).

The goals of the pilot implementation were ambitious, with the intent of putting the best foot forward. With that in mind, a full day conference with four streams of talks was held. In addition to the talks, there were industry vendors and problem pitches being made. The goal of this implementation was to provide a high quality professional experience to make it clear to the students that this was a serious issue and not something that could be ad-hoc.

The four streams included two of industry speakers from different companies (one on technical skills related to their industry, and one providing broader perspectives), one of faculty from different departments in the university, and one from alumni working in industry. The goal of these talks was to re-iterate the important aspects of the design process such as identifying needs and working in teams, and their impact on physical tangible products. In addition, talks regarding technical skills were also scattered throughout the streams. These talks would range from hardware debugging methods applied in industry to how to develop basic neural networks.

Another important aspect of EngCon was broad exposure to industry. For many students, their default is to go to the internet to source parts and equipment for their projects. This often takes them to overseas suppliers that have long lead times, or that have questionable quality. Running parallel to the talks throughout the day was a "vendor" area, as is common at many professional conferences. Suppliers from both in and outside the University set up booths to show supplies, equipment, and/or services that could be useful to groups as they move through their capstone projects. The booths showed the groups many different suppliers of commonly used products, with the goal that exposing students to quality (and in many cases, local) suppliers would ease some of the supply issues that students had encountered in the past.

The final major component of EngCon were the pitch sessions. These pitch sessions connected students with industry, and groups on campus to learn about problems that they are facing. These reflected real problems that needed to be solved and provided a connection between the groups and those individuals facing the problems. A full schedule for the 2017 EngCon event is available at [8].

\subsection{Results and Observations}

An anonymous survey was given to students at the end of the event to collect their feedback. Overall the feedback was encouraging, of the 47 respondents to the survey, 41 strongly agreed that EngCon should become an annual event. Response to the individual workshops was also quite positive, with the pitch sessions being a notable exception (many of the complaints related to the space used for this session, which was very loud). 
Although the organizing team was able to pull everything together, the impact of the first year was not as great as expected. The conference took place on the third Saturday in September, was free for students, and included lunch and a light supper for all attendees. Unfortunately with "no skin in the game", many students simply did not show up. With 300 students registered, only 150 came for the day. While it is obviously difficult to determine why these students didn't attend, the student organizers felt the biggest hurdle was the length of the event, and that it was held on a weekend.

While the students who filled in the surveys were fairly positive, in person, the talks were met with a more mixed response, with some talks being very well attended and some nearly empty. Feedback from the students generally pointed to issues with timing as it relates to the capstone project itself. They felt some of the topics were either too late (for 4A students), or the topics were too far in the future (for 3B students). The following comment from a student on the survey sums up nicely how many students felt:

EngCon was a great event. I strongly encourage it's adoption as an annual 'reintroduction' of the capstone project. I think that $3 B$ students would benefit the most from this event, since they are starting to think about their capstone projects but are not yet committed to forming teams or selecting project goals. I imagine that some $4 A$ students are too invested in a project, even at this point during the term to be able to make full use of some of the suggestions provided at EngCon. Professor Bedi's closing remarks were very accurate: the rigor of term-to-term engineering school takes its toll and ... EngCon was a great way to remind us what we're working towards.

\section{SECOND ITERATION}

For the second iteration, EngCon was scaled down considerably to only one (shorter) stream of presentations. This made the event a smaller commitment for students, and improved its sustainability for the future. The conference took place on the evening of Monday, September 24 , and was open to all $3^{\text {rd }} / 4^{\text {th }}$ year engineering students at Waterloo. For the second iteration of EngCon, the focus of the talks was narrowed to lead students through the first three steps in the Engineering Design Process as outlined by [9]: identify the need, research the need, and develop possible solution(s). The full schedule for the 2018 conference can be seen in Table 1 below.

A number of improvements were made to the format based on the feedback from 2017. One of the most important changes related to the venue used: the entire event took place in one location in 2018 with much better acoustic and $\mathrm{A} / \mathrm{V}$ capabilities. This greatly simplified advertising and promotion of the event, removed the burden of coordinating room bookings with multiple parties on campus, and removed the confusion when moving from one part of the building to another (or to another building entirely).

Table 1 EngCon 2018 schedule

\begin{tabular}{|l|l|}
\hline Time & Session (Presenter) \\
\hline $5: 00 \mathrm{pm}$ & Opening Remarks \\
\hline $5: 15 \mathrm{pm}$ & $\begin{array}{l}\text { Team Formation (Prof. Ken McKay, } \\
\text { Management Sciences) }\end{array}$ \\
\hline $5: 45 \mathrm{pm}$ & $\begin{array}{l}\text { Urgent, Pervasive, Important: Problem- } \\
\text { Centric Design (Prof. Derek Wright, ECE) }\end{array}$ \\
\hline $6: 15 \mathrm{pm}$ & Supper and socialize \\
\hline $6: 45 \mathrm{pm}$ & $\begin{array}{l}\text { From Pitch to Prototype, Design Good } \\
\text { Experience (Prof. Carolyn MacGregor, } \\
\text { Systems Design Engineering) }\end{array}$ \\
\hline $7: 15 \mathrm{pm}$ & $\begin{array}{l}\text { Build, and they will come? (Fayez Khan, } \\
\text { UV Pure Technologies) }\end{array}$ \\
\hline $7: 45 \mathrm{pm}$ & \#startup Lessons (Jay Shah, Velocity) \\
\hline $8: 15 \mathrm{pm}$ & $\begin{array}{l}\text { GM Problem Pitch (Parisa Golchoubian, GM } \\
\text { Canada) }\end{array}$ \\
\hline $8: 30 \mathrm{pm}$ & Ask-an-Expert Mixer \\
\hline $9: 30 \mathrm{pm}$ & Closing Remarks \\
\hline
\end{tabular}

\subsection{Results and Observations}

With the improved format, and coordinated advertising with the Dean of Engineering's Office, over 200 students attended EngCon in 2018 (out of 332 registrations). In addition to the presenters, the convention also featured booths from six suppliers, including Keysight Technologies, Gap Wireless, Elmwood Electronics, and campus suppliers. The evening was capped off with GM Canada launching their Capstone Design Seed Fund with the problem statement: "How can we make the Autonomous Experience more inclusive and accessible?".

A similar anonymous survey was run again to capture student feedback, and while only 31 responses were collected, the feedback was overwhelmingly positive, with $87 \%$ of respondents strongly agreeing that EngCon should become an annual event. Feedback on the presentations was positive, but some concerns were noted: fourth year students felt the talk on team formation was too late to be useful to them (many of them form their teams in third year), with one student saying:

Super useful event in terms of getting prepared for Capstone. I think it should be marketed mostly at $3 A / B$ students rather than $4^{\text {th }}$ years. That wil give them time to use the knowledge. Still useful for $4^{\text {th }}$ years, but only in terms of reflecting on what they could have done better at the beginning of capstone.

Some students also felt that some talks placed too much emphasis on commercializing capstone projects, which had less appeal to them. Anecdotal feedback from the industry attendees was also very positive, with many committing to support the event in the future. 


\section{FUTURE WORK}

In response to the comments from students that some of the content presented at EngCon was too late for fourth year students, the Ideas Clinic has planned a different workshop-based intervention for 3B students. Two internal teaching enhancement grants were awarded to develop this initiative, which will focus on developing student skills in needs identification and needs assessment. A pilot of this workshop was offered to Management, Electrical and Computer, and Mechanical and Mechatronics Engineering students in the winter 2019 term. As part of the workshop, students visited the fourth year capstone symposia of the students a year ahead of them in the program, and conducted an informal assessment of their peers' problem statements. While much work needs to be done to develop this idea further, this earlier intervention will allow EngCon to shift its focus on the later stages of the design cycle, better aligning the timing of that content to where fourth year students are in their capstone projects at that point in September.

\section{CONCLUSIONS}

To address deficiencies in the capstone process for fourth year engineering students, a team of staff and faculty at the University of Waterloo developed a conference to connect students with peers from other programs, instructors from across the faculty, and suppliers that would be useful in their capstone projects. The pilot of this conference was offered to students in September of 2017, and a survey was given to attendees to collect feedback. A number of refinements were made to the conference for the 2018 offering, shrinking the event from an entire day to one evening, and narrowing the focus of the talks to the early stages of the design process. Attendance in 2017 was strong, with 150 students attending, and improved to over 200 in 2018. Feedback from students, presenters, and industry attendees has been positive about the event, with most agreeing that it should continue in future years.

The general feeling of the organizers after running EngCon in 2018 was that it had reached a format that is sustainable for the future. While there are some planned tweaks to the order of presentations that will be implemented in 2019 (end the night with food instead of breaking up the presentations!), and the content of some presentations will be adjusted to seek a better match for both 3B and 4A students, little else will need to change.

\section{Acknowledgements}

This work would not have been possible without the help of the many people who helped plan and implement this idea. Special thanks to the organizers of both events: Jen Rathlin, Derek Wright, Julia Chernushevich, Hannah Gautreau, Kristina Lee, Victoria Alderson, and Ada Hurst.
A special thank you to all the presenters: Ken McKay, Derek Wright, Carolyn MacGregor, Fayez Khan, Jay Shah, Parisa Golchoubian and GM Canada, Peter Schweiger, Gary Mousseau, Aaron Shull, Andrew Finkle, Riccardo Caimano, Jim Baleshta, Kevin Wright, Trevor Smouter, Steve Lambert, David Wang, Mike Tsay, Mark Crowley, and Kate Wilhelm.

Lastly, the authors would like to acknowledge the financial support of Electrical and Computer Engineering and Mechanical and Mechatronics Engineering.

\section{References}

[1] Velocity, "How a fourth-year design project became a startup: The story of Palette," 6 April 2017. [Online]. Available: http://velocity.uwaterloo.ca/2017/04/howa-fourth-year-design-project-became-a-startup-thestory-of-palette/. [Accessed 8 January 2019].

[2] P. Frise, G. Rohrauer, B. Minaker and W. Altenhof, "Identifying the Design Engineering Body of Knowledge," in International Conference on Engineering Design (ICED), Stockholm, 2003.

[3] G. Pahl and W. Beitz, Engineering design: A systematic approach, Springer Science \& Business Media, 2013.

[4] R. Dam and T. Siang, "5 Stages in the Design Thinking Process," March 2019. [Online]. Available: https://www.interactiondesign.org/literature/article/5-stages-in-the-designthinking-process. [Accessed 24 April 2019].

[5] G. C. Andrews, J. Aplevich and R. Fraser, Introduction to Professional Engineering in Canada, Toronto: Pearson Canada, 2018.

[6] R. Kaufman and F. W, Needs Assessment: Concept and Application, Educational Technology Publications, 1979.

[7] J. Grant, "Learning needs assessment: assessing the need," BMJ, vol. 156, p. 324, 2001.

[8] Engineering Ideas Clinic, "EngCon 2017 Schedule," University of Waterloo, [Online]. Available: https://uwaterloo.ca/engineering-ideasclinic/engcon/engcon-2017-schedule. [Accessed 24 April 2019].

[9] Dr. David P. Driscoll, Commissioner of Education, "Massachusetts Science and Technology/Engineering Curriculum Framework," Massachusetts Deparment of Education, Malden, MA, 2006. 